\title{
On the effects of temperature on the strength of $\mathrm{H}_{2} \mathrm{SO}_{4}$-doped ice single crystals
}

\author{
Xiang LI, Daniel ILIESCU, Ian BAKER \\ Thayer School of Engineering, Dartmouth College, Hanover, New Hampshire 03755-8000, USA \\ E-mail: ian.baker@dartmouth.edu
}

\begin{abstract}
Previously, it was shown that the reduction in peak stress of single crystal ice at $-20^{\circ} \mathrm{C}$ due to $\mathrm{H}_{2} \mathrm{SO}_{4}, \Delta \sigma$, could be described by $\Delta \sigma=k C^{1 / 2}$, where $C$ is the sulfuric acid concentration and $k$ is a constant. Here we show that the strength reduction due to $\mathrm{H}_{2} \mathrm{SO}_{4}$ is more general and that the reduction is greater as the temperature decreases. $\Delta \sigma$ was again found to be proportional to $C^{1 / 2}$ at $-10^{\circ} \mathrm{C}$, but $k$ at $-10^{\circ} \mathrm{C}$ was significantly less than at $-20^{\circ} \mathrm{C}$.
\end{abstract}

\section{INTRODUCTION}

In ice $I_{h}$, adjacent (0001) slip planes are connected via randomly oriented hydrogen bonds. Glen (1968) suggested that this proton disorder presents the major obstacle to dislocation motion and, thus, for a dislocation to glide, the hydrogen bonds need to be appropriately oriented. This bond reorientation takes place by the movement of $\mathrm{H}_{3} \mathrm{O}^{+}$ and $\mathrm{OH}^{-}$ions and $\mathrm{L}-$ and D-Bjerrum defects. Hence, the introduction of extrinsic point defects into ice, by the addition of soluble impurities, should increase dislocation mobility and make the ice softer. While measurements on increased dislocation mobility in doped ice have produced either negative or inconclusive results (Maï and others, 1978; Shearwood and Whitworth, 1992; Hu and others, 1995), impurities do appear to increase the dislocation density in ice, although it is not clear why (Jones and Gilra, 1972, 1973a,b; Oguro, 1988; Hu and others, 1995; Trickett and others, 2000). Several studies have clearly shown that small concentrations (a few ppm) of the acids $\mathrm{HF}, \mathrm{HCl}$ and $\mathrm{H}_{2} \mathrm{SO}_{4}$ decrease the strength of ice single crystals dramatically (Jones, 1967; Jones and Glen, 1969; Nakamura and Jones, 1970, 1973; Trickett and others, 2000) and, at least for $\mathrm{H}_{2} \mathrm{SO}_{4}$, that this leads to a concomitant increase in ductility (Trickett and others, 2000).

$\mathrm{H}_{2} \mathrm{SO}_{4}$ is of interest since it is present in natural ice, arising from aerosols produced by volcanoes and anthropogenic sources. In recent work, we demonstrated that at $-20^{\circ} \mathrm{C}$, even though $\mathrm{H}_{2} \mathrm{SO}_{4}$ decreases the strength of ice single crystals, it has no effect on the stress exponent, $n$, in the relationship between the shear strain rate, $\dot{\gamma}$, and peak shear stress, $\tau$, i.e. $\dot{\gamma} \propto \tau^{n}$ (Baker and others, 2000). It was also shown that at $-20^{\circ} \mathrm{C}$ the reduction in peak resolved shear stress (RSS) due to the presence of $\mathrm{H}_{2} \mathrm{SO}_{4}, \Delta \sigma$, was related to the concentration, $C$, through $\Delta \sigma=k C^{1 / 2}$, where $k$ is a constant (Trickett and others, 2000). In this paper, we extend our previous work on the effects of doping on ice single crystals and describe the effects of doping with $\mathrm{H}_{2} \mathrm{SO}_{4}$ on $n$ and $k$ at $-10^{\circ} \mathrm{C}$ and $-30^{\circ} \mathrm{C}$.

\section{EXPERIMENTAL}

Both high-purity ice crystals and $\mathrm{H}_{2} \mathrm{SO}_{4}$-doped ice crystals were grown in a cold room at the Ice Research Laboratory, Thayer School of Engineering, Dartmouth College. All the doped ice crystals were made from deionized water mixed with $\mathrm{H}_{2} \mathrm{SO}_{4}$ in 5 gal $(20 \mathrm{~L})$ Nalgene tanks. The concentration of $\mathrm{H}_{2} \mathrm{SO}_{4}$ in each specimen was determined after mechanical testing by melting the specimen and measuring the $\mathrm{pH}$ of the resulting solution with a probe calibrated in the range of interest. The water-filled tanks were placed in a $1-2^{\circ} \mathrm{C}$ cold room for 24 hours to equilibrate the water temperature; 24 hours is a good time in which to get bubble-free ice. After equilibration, the cold-room temperature was changed to $-2^{\circ} \mathrm{C}$ for 10 days. The sides and the bottom of the tank were insulated with Armaflex foam in order to minimize the radial heat exchange and to force the ice to grow more-or-less unidirectionally from the open top. Large ice pucks $(28 \mathrm{~cm}$ diameter, $13 \mathrm{~cm}$ high) of various concentrations of $\mathrm{H}_{2} \mathrm{SO}_{4}$ were grown. Each puck contained three to five large crystals with the $c$ axes oriented quasi-parallel to the growth direction, which was downward. The same method was used to grow undoped ice. Polarized illumination was used to identify and trace the boundaries of the large crystals (Hobbs, 1974), and eventually the large single crystals were cut out using a precision bandsaw. If needed, the ice was stored in plastic bags and put in $\mathrm{a}-10^{\circ} \mathrm{C}$ cold room.

After an ice single crystal was chosen, its orientation was further examined by etch-pitting with a Formvar solution (Higuchi, 1958). The oriented grains were then cut out using a bandsaw to have the basal plane (marked with a hexagon in Fig. 1) tilted either at $45^{\circ}$ or $3^{\circ}$ from the top surface, with $(11 \overline{2} 0)$ planes on the side surface. The final orientation of the single crystal was confirmed by cutting a thin section cut from one end and analyzing it using the Rigby stage.

A horizontal milling machine was used to shape the surfaces of specimens to obtain a final sample of $20 \mathrm{~mm} \times 25 \mathrm{~mm} \times 60 \mathrm{~mm}$.

All mechanical tests were performed at a constant strain rate using a hydraulic MTS uniaxial testing machine located in a cold room. Two sets of tests were performed. First, both for crystals containing $3.2 \mathrm{ppm}_{2} \mathrm{SO}_{4}$ and for the undoped ice, tests were performed over a range of strain rates from $3 \times 10^{-7} \mathrm{~s}^{-1}$ to $3 \times 10^{-4} \mathrm{~s}^{-1}$ at $-10^{\circ} \mathrm{C}$ and $-30^{\circ} \mathrm{C}$. In all these tests the single crystals had the basal plane angle $\theta=45^{\circ}$. Second, at $-10^{\circ} \mathrm{C}$, tests were performed on crystals with four different concentrations of $\mathrm{H}_{2} \mathrm{SO}_{4}$ under an axial strain rate of $1 \times 10^{-5} \mathrm{~s}^{-1}$. All these tests had the basal plane angle $\theta=3^{\circ}$ for direct comparison to previous tests by Trickett and others (2000). LabVIEW data acquisition software was used to collect the load and displacement from the tests. The strain-rate error was approximately $\pm 2 \%$ and the measured peak stress was accurate to within $\pm 5 \%$. 


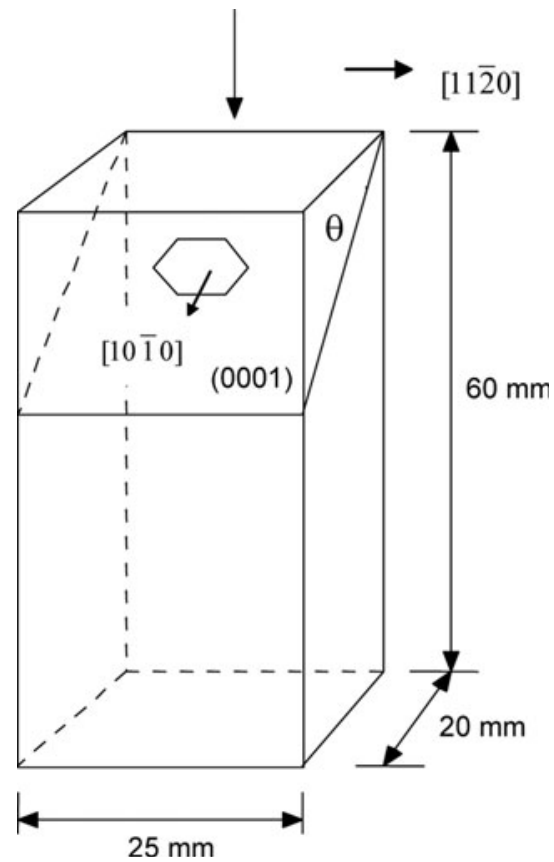

Fig. 1. The dimensions and orientation of the ice single crystals. The plane with a hexagon indicates the orientation of the basal plane, which was tilted to either $\theta=45^{\circ}$ or $\theta=3^{\circ}$ from the top surface.
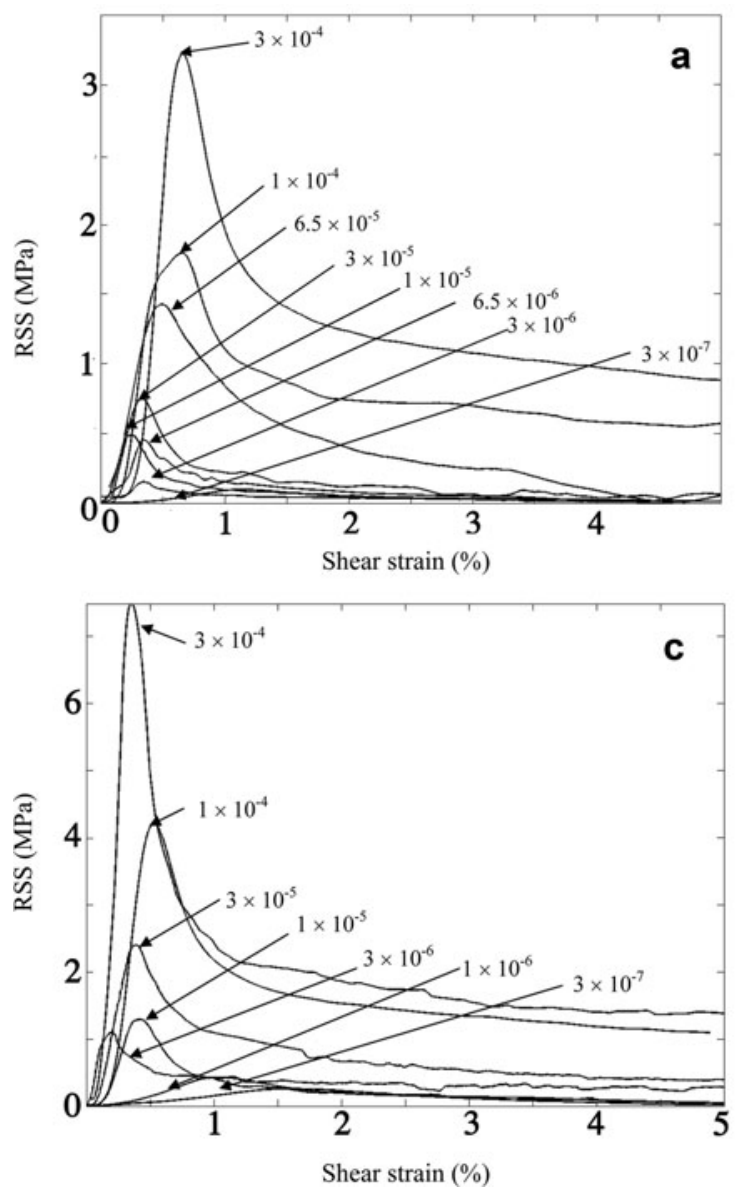

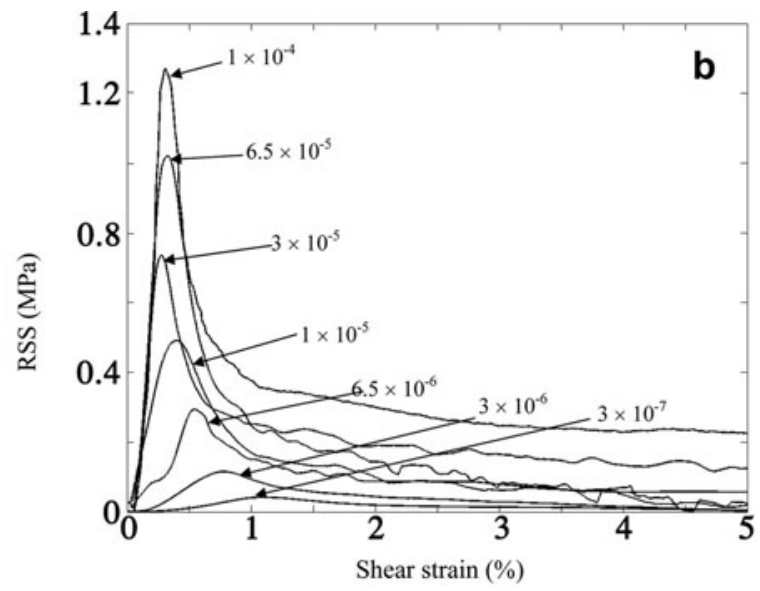

\section{RESULTS AND DISCUSSION}

Figure 2 shows the RSS on the basal plane plotted against shear strain for compression tests at $-10^{\circ} \mathrm{C}$ and $-30^{\circ} \mathrm{C}$ performed at different axial strain rates for high-purity ice crystals and $\mathrm{H}_{2} \mathrm{SO}_{4}$-doped ice crystals. All these tests were performed with the basal plane tilted to $45^{\circ}$. Common to all tests, the curves show a linearly rising stress followed by a sharply declining stress after a peak, the decline in stress decreasing with increasing strain. The curves demonstrate dramatic decreases in peak stress and subsequent flow stress with decreasing strain rate. The peak stress and subsequent flow stresses are much higher at $-30^{\circ} \mathrm{C}$ for a given strain rate than those at $-10^{\circ} \mathrm{C}$.

The stress exponent, $n$, was obtained by linear regression from plots of $\dot{\gamma}=A \tau^{n}$ or $\log \dot{\gamma}=\log A+n \log \tau$, where $\dot{\gamma}$ is the shear strain rate and $\tau$ is the corresponding maximum RSS at constant temperature. Figure 3 is a logarithmic plot of resolved shear strain rate versus peak RSS for the data obtained here at $-10^{\circ} \mathrm{C}$ and $-30^{\circ} \mathrm{C}$, and for data at $-20^{\circ} \mathrm{C}$ from Baker and others (2000).

Three important points need to be emphasized. First, at any given temperature the strength is decreased by the addition of $\mathrm{H}_{2} \mathrm{SO}_{4}$ (cf. Fig. 2a and b and Fig. 2c and d). This can also be clearly seen in Figure 4 which compares the RSS-shear-strain curves for high-purity and $\mathrm{H}_{2} \mathrm{SO}_{4}$-doped (3.2 ppm) ice single crystals with $\theta=45^{\circ}$ when tested with an axial strain rate of $1 \times 10^{-5} \mathrm{~s}^{-1}$ at $-30^{\circ} \mathrm{C}$. Second, for a

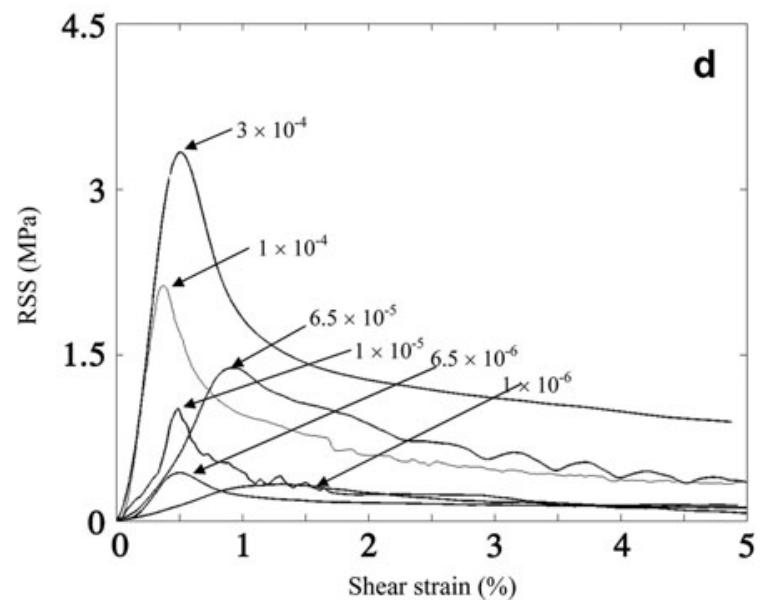

Fig. 2. Typical RSS-shear-strain curves at various axial strain rates (shown in $\mathrm{s}^{-1}$ ) for high-purity ice single crystals with the $c$ axis at $45^{\circ}$ to the

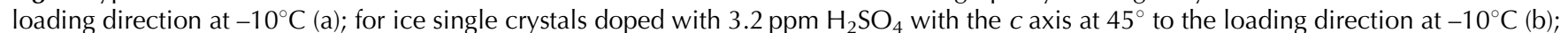
for high-purity ice single crystals with the $c$ axis at $45^{\circ}$ to the loading direction at $-30^{\circ} \mathrm{C}$ (c); and for ice single crystals doped with 3.2 ppm $\mathrm{H}_{2} \mathrm{SO}_{4}$ with the $c$ axis at $45^{\circ}$ to the loading direction at $-30^{\circ} \mathrm{C}(\mathrm{d})$. 


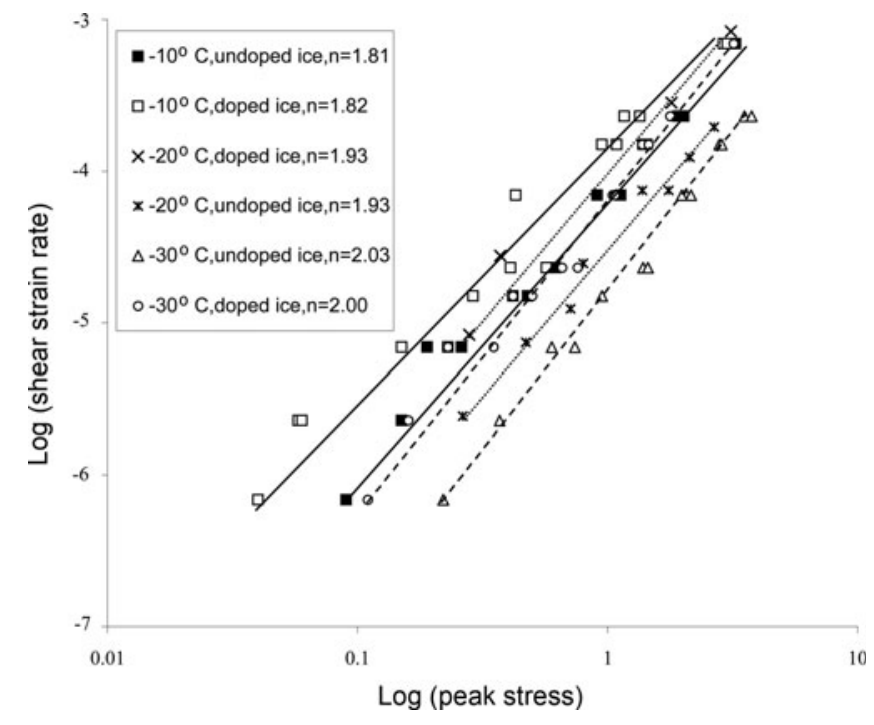

Fig. 3. Graph on log-log scales, of shear strain rate versus peak stress, showing a comparison between the $n$ values (slopes) of undoped and $\mathrm{H}_{2} \mathrm{SO}_{4}$-doped ice single crystals at different temperatures. The data at $-20^{\circ} \mathrm{C}$ are from Trickett and others (2000) and are for $3.4 \mathrm{ppm} \mathrm{H}_{2} \mathrm{SO}_{4}$ (not $6.8 \mathrm{ppm}$ as noted in that publication).

particular temperature, the stress exponent is unaffected by doping. Third, the stress exponent appears to increase slightly with decreasing temperature, i.e. from 1.81-1.82 at $-10^{\circ} \mathrm{C}$ to 1.93 at $-20^{\circ} \mathrm{C}$ (Baker and others, 2000) and 2.02.03 at $-30^{\circ} \mathrm{C}$. These $n$ values are close to those obtained by Jones and Brunet (1978), who performed constant strain-rate compression tests on single crystals. In their work, $n=2.01 \pm 0.04$ at $-10^{\circ} \mathrm{C}$ and $n=2.07 \pm 0.08$ at $-20^{\circ} \mathrm{C}$.

In order to further examine the weakening effect, ice single crystals doped with various concentrations of $\mathrm{H}_{2} \mathrm{SO}_{4}$ were strained under compression at constant strain rate in order to obtain the relationship between the reduction in strength due to $\mathrm{H}_{2} \mathrm{SO}_{4}$ and the dopant level. Tests were performed at $10^{\circ} \mathrm{C}$ on single crystal specimens with the basal plane tilted to $3^{\circ}$ for direct comparison to previous tests at $-20^{\circ} \mathrm{C}$ (Trickett

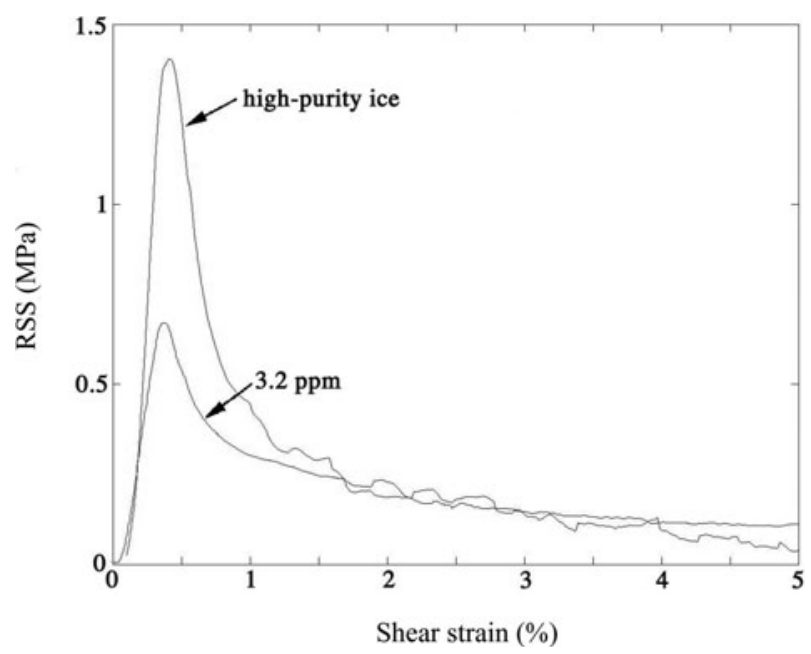

Fig. 4. RSS-shear-strain curves for high-purity and $3.2 \mathrm{ppm}_{2} \mathrm{SO}_{4}$ doped ice single crystals with $\theta=45^{\circ}$ at an axial strain rate of $1 \times 10^{-5} \mathrm{~s}^{-1}$ at $-30^{\circ} \mathrm{C}$.

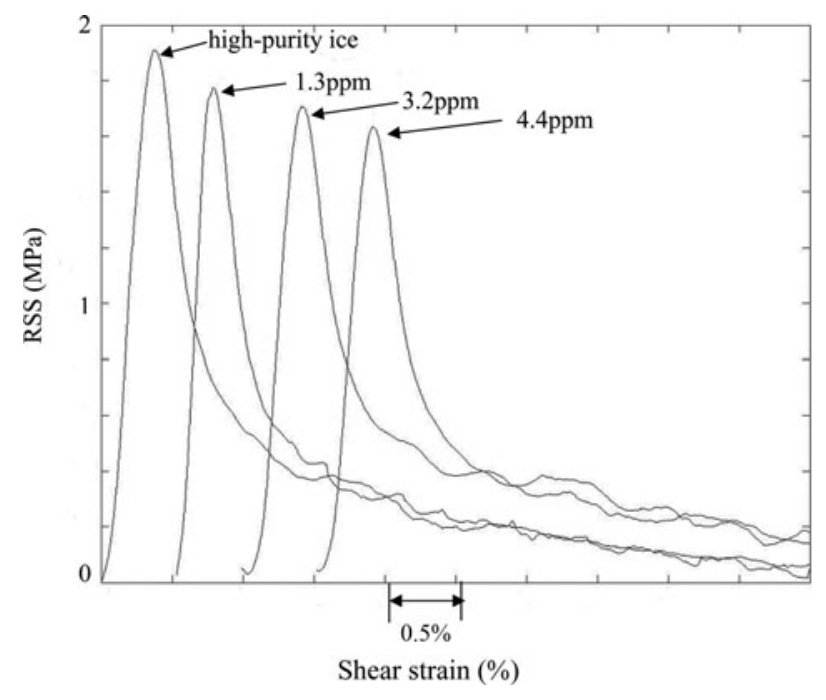

Fig. 5. Comparison between the RSS-shear-strain curves for highpurity ice single crystals and ice single crystals doped with various concentrations of $\mathrm{H}_{2} \mathrm{SO}_{4}$. The basal plane orientation is $\theta=3^{\circ}$; axial strain rate $=1 \times 10^{-5} \mathrm{~s}^{-1}$; temperature $=-10^{\circ} \mathrm{C}$. The curves are offset along the strain axis.

and others, 2000). Figure 5 clearly shows that the higher the dopant level, the softer is the doped ice.

There are two possible explanations for this softening. The $\mathrm{H}_{2} \mathrm{SO}_{4}$ may increase the dislocation mobility due to the addition of two $\mathrm{H}^{+}$ions from each $\mathrm{H}_{2} \mathrm{SO}_{4}$ molecule (Glen, 1968), or it may increase the grown-in dislocation density (Trickett and others, 2000). The difference between the critical RSS for high-purity ice and that for $\mathrm{H}_{2} \mathrm{SO}_{4}$-doped ice at $-10^{\circ} \mathrm{C}$ is plotted as a function of $C^{1 / 2}$, where $C$ is the concentration of $\mathrm{H}_{2} \mathrm{SO}_{4}$ (Fig. 6). Data at $-20^{\circ} \mathrm{C}$ from Trickett and others (2000) are shown for comparison; note that the data in that publication have $\mathrm{H}_{2} \mathrm{SO}_{4}$ concentrations a factor of two too large, i.e. they are actually extrinsic $\mathrm{H}_{3} \mathrm{O}^{+}$concentrations.

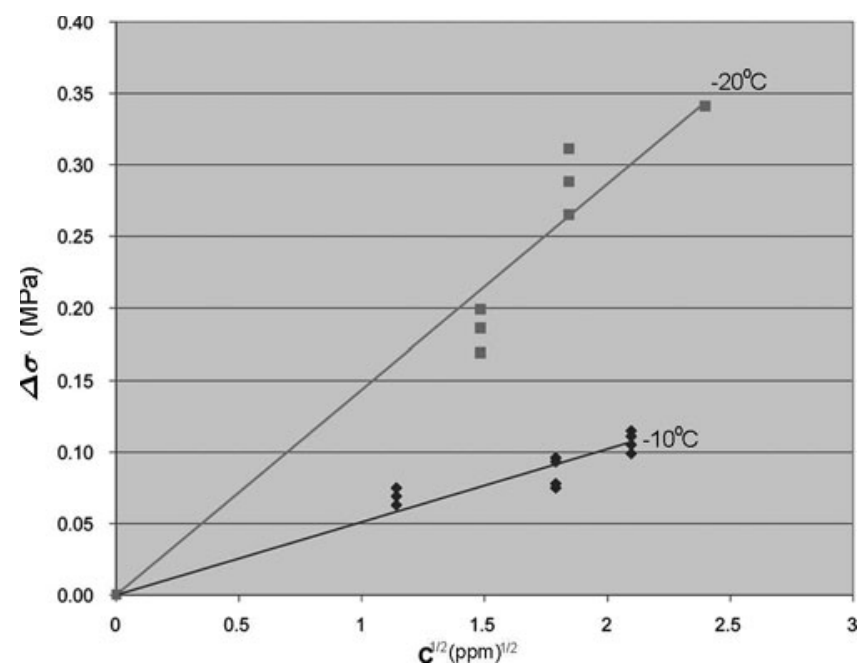

Fig. 6. Comparison of the reduction in peak RSS difference, $\Delta \sigma$, versus $C^{1 / 2}$ in ice single crystals compressed at $-10^{\circ} \mathrm{C}$ and $-20^{\circ} \mathrm{C}$ normalized to a shear strain rate of $1 \times 10^{-5} \mathrm{~s}^{-1}$. The data at $-20^{\circ} \mathrm{C}$ are from Trickett and others (2000). 
It is evident from Figure 6 that the softening effect at $-10^{\circ} \mathrm{C}$ is less than half that at $-20^{\circ} \mathrm{C}$. This is consistent with Glen's model (Glen, 1968), i.e. the softening from $\mathrm{H}_{2} \mathrm{SO}_{4}$ arises from the extrinsic $\mathrm{H}_{3} \mathrm{O}^{+}$ions, which aid dislocation motion, and these extrinsic ions constitute a smaller proportion of the total $\mathrm{H}_{3} \mathrm{O}^{+}$ion concentration, i.e. extrinsic plus thermally produced (intrinsic), at $-10^{\circ} \mathrm{C}$. A final point concerns the scatter in the data in Figure 6. This may have two causes. First, slight misorientations in crystal orientation could affect the strength. Second, there are undoubtedly variations in $\mathrm{H}_{2} \mathrm{SO}_{4}$ concentrations within each single crystal.

\section{CONCLUSIONS}

It has been shown that $\mathrm{H}_{2} \mathrm{SO}_{4}$ decreases the strength of ice crystals at $-10^{\circ} \mathrm{C}$ and $-30^{\circ} \mathrm{C}$ but does not affect the stress exponent. The decrease in peak stress due to $\mathrm{H}_{2} \mathrm{SO}_{4}$ is proportional to the square root of the sulfuric acid concentration, with the decrease in strength being greater at $-20^{\circ} \mathrm{C}$ than at $-10^{\circ} \mathrm{C}$. The results are consistent with Glen's model for dislocation motion in ice, but other effects of impurities or dislocations (e.g. increasing their density) cannot be excluded.

\section{ACKNOWLEDGEMENTS}

This research was supported by US National Science Foundation (NSF) grants OPP-0738975 and OPP-0440523 and US Army Research Office (ARO) grants DAAD 19-00-10444 and 51065-EV. The views and conclusions contained herein are those of the authors and should not be interpreted as representing official policies, either expressed or implied, of the NSF, ARO or the US Government.

\section{REFERENCES}

Baker, I., Y.L. Trickett and P.M.S. Pradhan. 2000. The effect of $\mathrm{H}_{2} \mathrm{SO}_{4}$ on the stress exponent in ice single crystals. In Maltman, A.J., B. Hubbard and M.J. Hambrey, eds. Deformation of glacial materials. London, Geological Society, 39-45. (Special Publication 176.)
Glen, J.W. 1968. The effect of hydrogen disorder on dislocation movement and plastic deformation of ice. Phys. Kondens. Mater., 7(1), 43-51.

Higuchi, K. 1958. The etching of ice crystals. Acta Metall., 6(10), 636-642.

Hobbs, P.V. 1974. Ice physics. Oxford, etc., Clarendon Press.

Hu, X., K. Jia, P. Liu, I. Baker and D. Black. 1995. Dislocation mobility in $\mathrm{HCl}$-doped ice. Mater. Res. Soc. Symp. Proc., 375, 287-292.

Jones, S.J. 1967. Softening of ice crystals by dissolved fluoride ions. Phys. Lett., 25(5), 366-367.

Jones, S.J. and J.G. Brunet. 1978. Deformation of ice single crystals close to the melting point. J. Glaciol., 21(85), 445-455.

Jones, S.J. and N.K. Gilra. 1972. Increase of dislocation density in ice by dissolved hydrogen fluoride. Appl. Phys. Lett., 20(8), 319-320.

Jones, S.J. and N.K. Gilra. 1973a. Dislocations in ice observed by Xray topography. In Whalley, E., S.J. Jones and L.W. Gold, eds. Physics and chemistry of ice. Ottawa, Ont., Royal Society of Canada, 344-349.

Jones, S.J. and N.K. Gilra. 1973b. X-ray topographical study of dislocations in pure and HF-doped ice. Philos. Mag., 27(2), 457-472.

Jones, S.J. and J.W. Glen. 1969. The effect of dissolved impurities on the mechanical properties of ice crystals. Philos. Mag. 19(157), 13-24.

Maï, C., J. Perez, J. Tatibouët and R. Vassoille. 1978. Vitesse des dislocations dans la glace dopée avec HF. J. Phys. [Paris] Lett., 39(17), 307-310.

Nakamura, T. and S.J. Jones. 1970. Softening effect of dissolved hydrogen chloride in ice crystals. Scripta Metall., 4(2), 123-126.

Nakamura, T. and S.J. Jones. 1973. Mechanical properties of impure ice crystals. In Whalley, E., S.J. Jones and L.W. Gold, eds. Physics and chemistry of ice. Ottawa, Ont., Royal Society of Canada, 365-369.

Oguro, M. 1988. Dislocations in artificially grown single crystals of ice. In Higashi, A., ed. Lattice defects in ice crystals: X-ray topographic observations. Sapporo, Hokkaido University Press, $27-47$

Shearwood, C. and R.W. Whitworth. 1992. The velocity of dislocations in crystals of $\mathrm{HCl}$-doped ice. Philos. Mag. A, 65(1), 85-89.

Trickett, Y.L., I. Baker and P.M.S. Pradhan. 2000. The effects of sulfuric acid on the mechanical properties of ice single crystals. J. Glaciol., 46(153), 239-243. 